\title{
Incidence and Distribution of Insect-Transmitted Cereal Viruses in Wheat in China from 2007 to 2019
}

\author{
Yan Liu, ${ }^{1}$ May Oo Khine, ${ }^{1}$ Peipei Zhang, ${ }^{2}$ Yumei Fu, ${ }^{1}$ and Xifeng Wang ${ }^{1, \dagger}$ \\ ${ }^{1}$ State Key Laboratory for Biology of Plant Diseases and Insect Pests, Institute of Plant Protection, Chinese Academy of Agri- \\ cultural Sciences, Beijing 100193, China \\ ${ }^{2}$ College of Life Sciences, Langfang Normal University, Langfang 065000, China
}

\begin{abstract}
Diseases caused by insect-transmitted viruses are the predominant constraint to wheat production worldwide. However, detailed knowledge of virus incidence and dynamics in China in recent years is very limited. Here, major wheat-growing regions of China were surveyed over 10 years for insect-transmitted viruses, and 2,143 samples were collected (in 2007 to 2015) and analyzed by molecular hybridization or multiplex reverse-transcription PCR for barley yellow dwarf viruses (BYDVs: BYDV-GAV, -GPV, and -PAV) and wheat dwarf virus (WDV). In a 4-year survey (2016 to 2019), the incidence of eight insect-transmitted viruses (BYDVs, WDV, wheat yellow striate virus [WYSV], barley

BYDV-GAV (29.0\% of the tested sample) was the most abundant, followed by BYDV-PAV (23.2\%) from 2007 to 2015. From 2016 to 2019, however, BYDV-PAV had become the predominant species (39.5\% positive of 952 samples tested), while the incidence of BYDVGAV (13.4\%) had declined. During the entire survey, the incidence of BYDV-GPV was very low in some locations in northwestern and northern China, and all eight viruses caused only local epidemics, not largescale outbreaks throughout China. Two new cereal-infecting rhabdoviruses, leafhopper-transmitted WYSV and planthopper-transmitted BYSMV, were also found in China in recent years.
\end{abstract} yellow striate mosaic virus [BYSMV], northern cereal mosaic virus [NCMV], and rice black-streaked dwarf virus [RBSDV]) was investigated, and BYDVs and WDV were widely distributed across China.
Keywords: cereals and grains, China, dynamics, field crops, incidence, insect-transmitted viruses, pathogen detection, viruses and viroids, wheat
More than 50 viruses infect wheat (Triticum aestivum L.) or other cereals worldwide and can cause significant yield losses (Rotenberg et al. 2016). Hemipteran insects (in particular, aphids, leafhoppers, and planthoppers) can transmit most of these viruses and play an important role in the epidemiology of wheat-infecting viruses that belong to the families Luteoviridae, Rhabdoviridae, and Geminiviridae (Hogenhout et al. 2008). In recent years, crop production may be more seriously threatened as climate changes lead to variations in the insect vector populations and the cereal viruses they transmit.

About 25 cereal aphid species can act as vectors of barley yellow dwarf viruses or cereal yellow dwarf viruses (BYDVs or CYDVs, respectively; hereafter BYDVs) in a persistent (circulative) manner (Ingwell and Bosque-Perez 2015). BYDVs belonging to the family Luteoviridae were shown to cause the most widespread and economically important virus diseases of cereals worldwide (Miller and Rasochová 1997). Among this group, BYDV-PAV, -PAS, -MAV, -kerII, and -kerIII have been assigned to the genus Luteovirus; CYDV-RPV (formerly BYDV-RPV), CYDV-RPS, and maize yellow dwarf virus-RMV (formerly BYDV-RMV) to the genus Polerovirus; and BYDV-GPV and BYDV-SGV remain unassigned (Krueger et al. 2013; Zhang et al. 2009). Some of the Chinese isolates of BYDVs seem to be serologically related to U.S. isolates but they differ slightly in their

${ }^{\dagger}$ Corresponding author: X. F. Wang; xfwang@ippcaas.cn

Funding: This work was financially supported by the National Key Research and Development Program of China (2016YFD0300705) and the National Natural Science Foundation of China (31871938 and 31861133020 ).

*The $\boldsymbol{e}$-Xtra logo stands for "electronic extra" and indicates that one supplementary table is published online.

The author(s) declare no conflict of interest.

Accepted for publication 17 December 2019.

C 2020 The American Phytopathological Society aphid-transmission patterns (Zhou et al. 1984). For example, BYDVGAV, transmitted nonspecifically by Schizaphis graminum and Sitobion avenae, has a strong serological reaction with BYDV-MAV-specific antiserum (Zhou et al. 1984). Therefore, it is considered to be a Chinese isolate of BYDV-MAV (Jin et al. 2004). The Chinese isolate of BYDV-PAV has a strong serological reaction with BYDV-PAV-NYspecific antiserum but is transmitted efficiently by Rhopalosiphum padi, S. graminum, and S. avenae and is highly divergent from other BYDVPAV isolates in its genomic sequence (F. Liu et al. 2007). On the other hand, BYDV-GPV, transmitted nonspecifically by $R$. padi and S. graminum, has no serological relationship with any BYDV species from the United States; however, the genomic structure is close to that of CYDV-RPV (Zhang and Zhou 1987; Zhang et al. 2009). Characteristic symptoms in BYDV-infected plants are yellowing of flag leaves and dwarfing of plant height.

The leafhopper Psammotettix alienus (Hemiptera: Cicadellidae) can vector wheat dwarf virus (WDV) (genus Mastervirus, family Geminiviridae), which occurs mainly in Europe, Asia, and Africa and causes severe damage to cereal crops (Kumar et al. 2015; Manurung et al. 2004; Parizipour et al. 2017). WDV can cause severely dwarfing and leaf discoloration, reduced available tillering, and sterility on wheat. Leaves of WDV-infected plant usually turn yellow and sometimes red. In China, WDV was first identified in 2004 and soon spread to most wheat-growing regions (Wang et al. 2019; Xie et al. 2007). More recently, we found a new rhabdovirus, wheat yellow striate virus (WYSV), which shares the same insect vector with WDV (Y. Liu et al. 2018). WYSV-infected wheat plants showed yellowing and mild chlorotic streaks along small veins on leaves. WYSV is the first wheat-infecting nucleorhabdovirus found to be transovarially transmitted by $P$. alienus with high efficiency, suggesting that $P$. alienus is likely of great importance in the spread of WYSV (Du et al. 2020).

The small brown planthopper (SBPH), Laodelphax striatellus (Hemiptera: Delphacidae), also transmits various cereal-infecting viruses, including northern cereal mosaic virus (NCMV), barley yellow striate mosaic virus (BYSMV), and rice black-streaked dwarf virus (RBSDV) (Liu et al. 2019; Nault and Ammar 1989). NCMV and BYSMV, two closely related viruses belonging to genus 
Cytorhabdovirus (family Rhabdoviridae) but with distinct differences in molecular and serological characteristics (Yan et al. 2015), are transmitted by SBPH in a circulative, propagative manner (Conti 1969; Tanno et al. 2000). Epidemics of wheat rosette dwarf disease caused by NCMV, which produce symptoms of severe stunting and leaf darkening on wheat, were reported in northern China during the 1970s but have been rare in the last 40 years (Wei et al. 2018). BYSMV on wheat in China was first reported in 2014 but has been sporadic in northern, northwestern, and eastern regions (Di et al. 2014; Yang et al. 2018), and causes yellowing, yellow striping, and diffused streaking, sometimes with stunting. In addition, RBSDV (genus Fijivirus, family Reoviridae), transmitted by L. striatellus in a persistent propagative manner (Zhang et al. 2001), has caused serious damage in rice and maize in China since 2008. Diseased wheat plants exhibited extreme dwarfing, leaf darkening or yellowing, and reduced or no spikes.

Symptoms of wheat viral diseases are indistinguishable in the field because infected plants generally exhibited yellowing, darkening, or stunting. To effectively monitor these viral diseases, we first surveyed wheat for insect-transmitted viruses in China from 2007 to 2015, targeting BYDVs and WDV by nucleic acid hybridization. From 2016 to 2019, we also monitored the incidence of WYSV, BYSMV, NCMV, and RBSDV in different regions of China by PCR. This study over 10 years provides key information on the prevalence and incidence of insect-transmitted cereal viruses in five distinct wheat-growing regions in China.

\section{Materials and Methods}

Sample collection. Two surveys in this study were conducted throughout most wheat-growing regions in China. The first involved screening wheat plants for BYDVs and WDV every 2 years from 2007 to 2015; in total, 2,143 samples were collected. During the second period, from 2016 to 2019,952 samples from the tested fields were evaluated for BYDVs and WDV, then further tested for the presence of WYSV, BYSMV, NCMV, and RBSDV. Wheat samples showing dwarfing, yellowing, yellow mosaic, stripe mosaic, and stunting were collected from randomly selected fields in different regions. A map indicating the locations of the sampling sites is provided in Figure 1: northwest (Hancheng, Shaanxi, $35.50^{\circ} \mathrm{N}, 110.50^{\circ} \mathrm{E}$; Yangling, Shaanxi, $34.29^{\circ} \mathrm{N}, 108.07^{\circ} \mathrm{E}$; Tianshui, Gansu, $34.60^{\circ} \mathrm{N}, 105.65^{\circ} \mathrm{E}$; Yinchuan, Ningxia, $38.36^{\circ} \mathrm{N}, 106.27^{\circ} \mathrm{E}$; Xining, Qinghai, $36.73{ }^{\circ} \mathrm{N}$, $101.76^{\circ} \mathrm{E}$; and Urumchi, Xinjiang, $43.99^{\circ} \mathrm{N}, 89.76^{\circ} \mathrm{E}$ ), north (Linfeng, Shanxi, $36.11^{\circ} \mathrm{N}, 111.52^{\circ} \mathrm{E}$; Taiyuan, Shanxi, $37.40^{\circ} \mathrm{N}, 112.54^{\circ} \mathrm{E}$; and Shijiazhang, Hebei, $38.11^{\circ} \mathrm{N}, 114.53^{\circ} \mathrm{E}$ ), central (Zhengzhou, Henan, $35.01^{\circ} \mathrm{N}, 113.71^{\circ} \mathrm{E}$; Kaifeng, Henan, $34.88^{\circ} \mathrm{N}, 114.51^{\circ} \mathrm{E}$; and Wuhan, Hubei, $30.49^{\circ} \mathrm{N}, 114.33^{\circ} \mathrm{E}$ ), southwest (Kunming, Yunnan, $25.36^{\circ} \mathrm{N}$, $103.12^{\circ} \mathrm{E}$; Guiyang, Guizhou, $26.51^{\circ} \mathrm{N}, 106.67^{\circ} \mathrm{E}$; Chengdu, Sichuan, $30.79^{\circ} \mathrm{N}, 104.21^{\circ} \mathrm{E}$; Mianyang, Sichuan, $31.39^{\circ} \mathrm{N}, 104.83^{\circ} \mathrm{E}$; and Lhasa, Tibet, $29.68^{\circ} \mathrm{N}, 91.25^{\circ} \mathrm{E}$ ), and east (Bozhou, Anhui, $33.49^{\circ} \mathrm{N}$, $116.25^{\circ} \mathrm{E}$; Jinan, Shandong, $36.71^{\circ} \mathrm{N}, 117.08^{\circ} \mathrm{E}$; and Yancheng, Jiangsu, $\left.37.42^{\circ} \mathrm{N}, 120.21^{\circ} \mathrm{E}\right)$.

Within each selected field, V-shaped or polygonal patterns were walked and samples were collected at predetermined distances

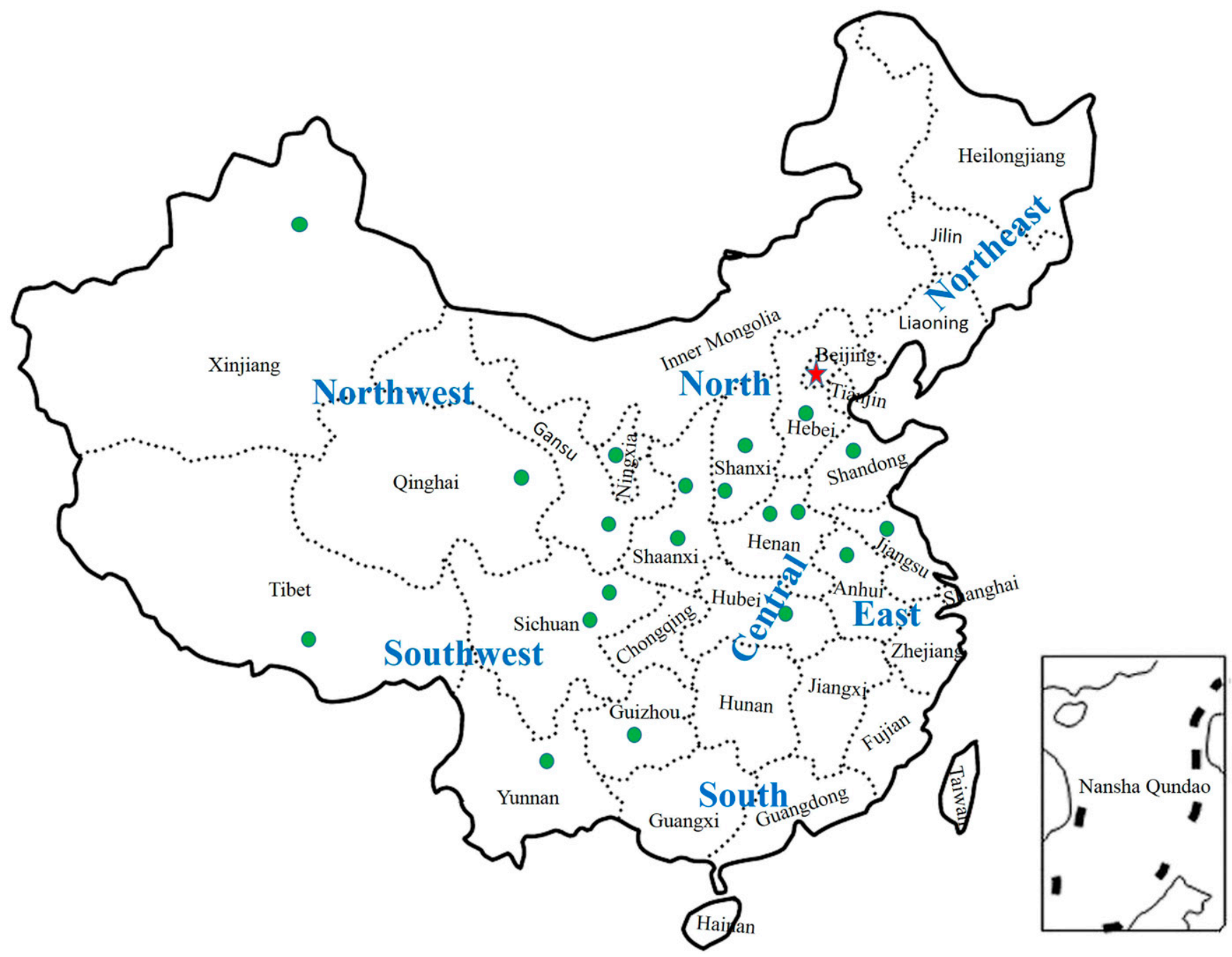

Fig. 1. Map of wheat fields sampled in China from 2007 to 2019. Dots indicate sampling sites in the northwest (Shaanxi, Gansu, Ningxia, Qinghai, and Xinjiang), north (Shanxi and Hebei), central (Henan and Hubei), southwest (Yunnan, Guizhou, Sichuan, and Tibet), and east (Anhui, Shandong, and Jiangsu). 
between samples $(20$ to $50 \mathrm{~m}$ ). Entire wheat plants with leaves were collected with soil, placed in individual plastic bags, and returned to the laboratory. After that, leaves with symptoms was selected and sealed in self-styled bags, then stored at $-70^{\circ} \mathrm{C}$ for following RNA extraction.

Virus source. For positive controls, BYDVs were isolated as viral sources and maintained in oat seedlings (cultivar Coast Black) by regular transfer to new plants via the dominant aphid vector transmission using $S$. graminum for both BYDV-GAV and GPV and $R$. padi for BYDV-PAV. Similarly, all hopper-vectored viruses (WDV, WYSV, RBSDV, NCMV, and BYSMV) were maintained in wheat cultivar Yangmai 12 via viruliferous leafhoppers or SBPH.

Total RNA extraction. For each sample, after deep-freezing with liquid nitrogen, $100 \mathrm{mg}$ of leaf tissue was homogenized three to four times in an automated tissue homogenizer (MP FastPrep-24) for $20 \mathrm{~s}$ each. Total RNA was extracted from homogenized tissue using TRIzol reagent (Invitrogen) according to the protocol. The RNA was suspended in $50 \mu \mathrm{l}$ of double-distilled $\mathrm{H}_{2} \mathrm{O}$ and stored at $-80^{\circ} \mathrm{C}$ before using. The quality and quantity of the extracted nucleic acids were assessed spectroscopically at 230, 260, and $280 \mathrm{~nm}$ (NanoDrop 2000 Spectrophotometer; Thermo Fisher).

Nucleic acid spot hybridization. In the first survey period, we detected BYDV-GAV, BYDV-GPV, BYDV-PAV, and WDV using the nucleic acid spot hybridization (NASH) method that we developed in previous studies (Jin et al. 2015; Y. Liu et al. 2007). For each test sample, $1.2 \mu \mathrm{l}$ of RNA was spotted onto a nylon membrane.
Total RNA from fresh leaves infected by the laboratory isolates of each BYDV and WDV served as positive controls and healthy plants as the negative control. The membrane was cross-linked by exposure to UV light for $3 \mathrm{~min}$. The digoxigenin (DIG) probes for each BYDV or WDV were generated by using the PCR DIG Probe Synthesis Kit (Roche) (Jin et al. 2015; Y. Liu et al. 2007). Primer sequences for each virus are listed in Supplementary Table S1. Prehybridization and hybridization were done as described in our previous studies (Jin et al. 2015; Y. Liu et al. 2007). The membrane was washed in $2 \times \mathrm{SSC}$ buffer $(1 \times \mathrm{SSC}$ is $0.15 \mathrm{M} \mathrm{NaCl}$ plus $0.015 \mathrm{M}$ sodium citrate $)$ with $0.1 \%$ sodium dodecyl sulfate (SDS) at $25^{\circ} \mathrm{C}$ for 10 min twice and then in $0.5 \times \mathrm{SSC}$ buffer with $0.1 \times \mathrm{SDS}$ at $68^{\circ} \mathrm{C}$ for $15 \mathrm{~min}$ twice. Hybridization was immunodetected with anti-DIG-AP fab fragments and colorimetrically detected using 5-bromo-4-chloro-3-indolyl phosphate/nitro blue tetrazolium, according to the manufacturer's instructions (Roche).

Reverse-transcription PCR. In the second survey period, samples were tested using three groups of multiplexed reverse-transcription (RT)-PCR assay with specific primers developed previously (Y. Liu et al. 2007; Zhang et al. 2017). Detection group I was used to detect BYDV-GAV, -PAV, and -GPV; group II for WDV and WYSV; and group III for BYSMV, NCMV, and RBSDV. All primer sequences used in multiplexed RT-PCR assay are listed in Supplementary Table S1. All primers were synthesized by Shanghai Sangon Corporation. For all RT-PCR assays, first-strand cDNA was synthesized from $2 \mu \mathrm{l}$ of total RNA initiated by random primers

Table 1. Incidence of barley yellow dwarf viruses (GAV, PAV, and GPV) and wheat dwarf virus (WDV) from 2007 to 2015 in symptomatic wheat samples from regions in China

\begin{tabular}{|c|c|c|c|c|c|c|c|c|}
\hline \multirow[b]{2}{*}{ Year, region } & \multirow[b]{2}{*}{ Total $^{\mathbf{a}}$} & \multicolumn{7}{|c|}{ Number of positive samples } \\
\hline & & GAV & PAV & GPV & GAV+PAV & PAV+GPV & GAV+GPV & WDV \\
\hline \multicolumn{9}{|l|}{2007} \\
\hline Northwest & 216 & 57 & 33 & 5 & 0 & 0 & 0 & 59 \\
\hline North & 137 & 62 & 8 & 25 & 0 & 3 & 0 & 22 \\
\hline Central & 72 & 18 & 20 & 2 & 0 & 0 & 0 & 13 \\
\hline Southwest & 97 & 42 & 18 & 6 & 0 & 1 & 0 & 13 \\
\hline East & 55 & 10 & 20 & 7 & 1 & 0 & 0 & 6 \\
\hline Combined & 577 & 189 & 99 & 45 & 1 & 4 & 0 & 113 \\
\hline \multicolumn{9}{|l|}{2009} \\
\hline Northwest & 189 & 106 & 14 & 6 & 1 & 0 & 0 & 29 \\
\hline North & 168 & 85 & 11 & 10 & 0 & 0 & 0 & 22 \\
\hline Central & 92 & 5 & 49 & 2 & 0 & 0 & 0 & 6 \\
\hline Southwest & 107 & 29 & 37 & 0 & 0 & 0 & 0 & 9 \\
\hline East & 67 & 9 & 29 & 3 & 0 & 0 & 0 & 6 \\
\hline Combined & 623 & 234 & 140 & 21 & 1 & 0 & 0 & 72 \\
\hline \multicolumn{9}{|l|}{2011} \\
\hline Northwest & 133 & 27 & 7 & 8 & 0 & 1 & 0 & 51 \\
\hline North & 62 & 13 & 7 & 6 & 0 & 0 & 0 & 4 \\
\hline Central & 25 & 5 & 12 & 0 & 1 & 0 & 0 & 1 \\
\hline Southwest & 65 & 14 & 28 & 0 & 3 & 0 & 0 & 3 \\
\hline East & 35 & 5 & 13 & 0 & 0 & 0 & 0 & 2 \\
\hline Combined & 320 & 64 & 67 & 14 & 4 & 1 & 0 & 61 \\
\hline \multicolumn{9}{|l|}{2013} \\
\hline Northwest & 74 & 15 & 3 & 1 & 0 & 0 & 0 & 10 \\
\hline North & 77 & 10 & 3 & 4 & 0 & 0 & 0 & 16 \\
\hline Central & 56 & 10 & 28 & 0 & 2 & 0 & 0 & 2 \\
\hline Southwest & 33 & 8 & 22 & 0 & 0 & 0 & 0 & 2 \\
\hline East & 47 & 5 & 25 & 0 & 0 & 0 & 0 & 7 \\
\hline Combined & 287 & 48 & 81 & 5 & 2 & 0 & 0 & 37 \\
\hline \multicolumn{9}{|l|}{2015} \\
\hline Northwest & 78 & 22 & 10 & 1 & 0 & 0 & 0 & 10 \\
\hline North & 148 & 48 & 38 & 4 & 9 & 0 & 0 & 17 \\
\hline Central & 38 & 2 & 26 & 0 & 1 & 0 & 0 & 2 \\
\hline Southwest & 36 & 8 & 19 & 0 & 0 & 0 & 0 & 1 \\
\hline East & 36 & 6 & 17 & 1 & 2 & 0 & 1 & 3 \\
\hline Combined & 336 & 86 & 110 & 6 & 12 & 0 & 1 & 33 \\
\hline Total & 2,143 & 621 & 497 & 91 & 20 & 5 & 1 & 316 \\
\hline
\end{tabular}

a Number of total samples. 
(TransGen), using Moloney Murine Leukemia Virus Reverse Transcriptase (Promega Corp.), according to the manufacturer's recommendations. Then, each cDNA $(2-\mu 1)$ sample was used in three sets of the multiplex PCR system in a total reaction volume of $25 \mu$ l containing $2.5 \mu \mathrm{l}$ of $10 \times$ PCR buffer $\left(1.5 \mathrm{mM} \mathrm{MgCl} \mathrm{Mg}_{2}\right.$, $2 \mu \mathrm{l}$ of $10 \mathrm{mM}$ dNTPs, $0.5 \mu \mathrm{l}$ of forward and reverse primers (10 $\mu \mathrm{M}$ each), and $1 \mathrm{U}$ of rTaq DNA polymerase $(5 \mathrm{U} / \mu \mathrm{l})$ (Takara). The PCR cycling program was $94^{\circ} \mathrm{C}$ for $3 \mathrm{~min} ; 35$ cycles of $94^{\circ} \mathrm{C}$ for $30 \mathrm{~s}$, approximately 52 to $58^{\circ} \mathrm{C}$ for $30 \mathrm{~s}$, and $72^{\circ} \mathrm{C}$ for $1 \mathrm{~min}$; and $72^{\circ} \mathrm{C}$ for $10 \mathrm{~min}$. RT-PCR products were separated electrophoretically in $1.0 \%$ agarose gel containing ethidium bromide for $30 \mathrm{~min}$. For PCR amplification, total RNA from each virus-inoculated plant kept in the laboratory was used as the respective positive control. For the negative control, distilled water was used instead of template cDNA.

\section{Results}

Monitoring of incidence of BYDVs and WDV from 2007 to 2015. NASH hybridization revealed that BYDVs and WDV were widely distributed in wheat-growing regions of China (all survey results are summarized in Table 1; only the results of samples from Shaanxi Province in 2013 are illustrated in Figure 2). From all samples with virus-like symptoms, $57.6 \%(1,235$ of 2,143$)$ were positive for BYDVs and $14.7 \%$ (316 of 2,143) for WDV (Table 1). Among the detected BYDVs, the most prevalent was BYDV-GAV (621 positives of 1,235 total, 50.3\%), followed by BYDV-PAV (497 of 1,235, $40.2 \%)$. BYDV-GPV was present in only $7.4 \%$ of the samples $(91$ of 1,235) (Table 1). In addition, various combinations of mixed infections (BYDV-GAV+GPV, BYDV-GAV+PAV, or BYDVPAV+GPV) were found in $2.1 \%$ of the samples $(26$ of 1,235$)$ (Table 1), and few samples were coinfected with BYDVs and WDV. Noticeably, BYDV-PAV gradually became more prevalent after 2011; 20.9\% of samples were infected in 2011, 28.2\% in 2013, and 32.7\% in 2015 (Fig. 3).

BYDV-GAV was the most frequently detected BYDV in the northwest (Shaanxi, Gansu, Ningxia, Qinghai, and Xinjiang) from 2007 to 2015. Its incidence in this region was highest in 2009 $(56.1 \%)$ and 20.3 to $28.2 \%$ in other years. Incidence of BYDVPAV remained relatively low, from 4.1 to $15.3 \%$ (average approximately 9.7\%), but BYDV-GPV was found at the lowest frequency (2.9\%). The highest WDV incidence was found in 2011 (38.3\%; 12.8 to $27.3 \%$ in other years) (Table 1). In the central region (Henan and Hubei), BYDV-PAV was the most common BYDV, averaging 47.7\% (135 positive samples), followed by BYDV-GAV at $14.4 \%$ and BYDV-GPV and BYDV mixtures both at $1.4 \%$. WDVpositive samples accounted for only $8.5 \%$ of all samples from this region (Table 1). In northern China (Shanxi and Hebei), BYDV-GAV was the dominant virus (average: $36.8 \%$ average of total samples) from 2007 to 2015 (range of annual means: 13.0 to $50.6 \%$ ). BYDV-PAV was detected in $11.3 \%$ of samples, and $7.6 \%$ of samples had BYDV-GPV (all from Shanxi). WDV was detected in $13.7 \%$ of all samples (range of annual means: 6.5 to 20.8\%) (Table 1). In southwestern China (Yunnan, Guizhou, Sichuan, and Tibet), BYDV-PAV and BYDV-GAV were the two most abundant viruses (36.7 and $29.9 \%$, respectively), followed by WDV (8.3\%), BYDV-GPV $(1.8 \%)$, and BYDV mixtures $(1.2 \%)$. In Tibet, BYDV-GAV was the only virus detected (Table 1). In eastern China (Anhui, Shandong, and Jiangsu), BYDV-PAV was dominant, in 43\% (104 of 240) of positive samples, followed by BYDV-GAV (14.6\%), BYDV-GPV (4.6\%), and BYDV mixtures (1.7\%). WDV was detected in $10 \%$ (24) of positive samples in this region (Table 1).

Monitoring of eight insect-transmitted viruses between 2016 and 2019. In the second survey from 2016 to 2019, 781 of 952 collected samples tested positive for at least one of the eight viruses, including BYDV-GAV, -GPV, and -PAV, WDV, WYSV, BYSMV, NCMV, and RBSDV (Table 2). The multiplex RT-PCR results of part of the samples from the north in 2019 are shown in Figure 4. Approximately $54.4 \%$ of the samples were infected by BYDVs, $13.9 \%$ by leafhopper-transmitted viruses (WDV and WYSV), and $13.9 \%$ by SBPH-transmitted viruses (BYSMV,
NCMV, and RBSDV) (Table 2). Among the tested BYDVs, BYDV-PAV was the most common (39.5\%, 376 of 952), followed by BYDV-GAV (13.4\%) and BYDV-GPV (1.1\%) (Table 2). Mixed infections with BYDVs were found in only four samples. The mean incidence for WDV was $10.0 \%$ and for WYSV was $3.9 \%$, and only two samples from Shaanxi Province had both viruses. Mean incidence was $7.9 \%$ for BYSMV, $5.3 \%$ for RBSDV, and $0.7 \%$ for NCMV (Table 2). Coinfections with BYSMV+ BYDV or RBSDV+BYDV were found in only 2 and 1 samples, respectively, collected from the northern region, while no samples were coinfected with NCMV+BYDV.

\section{Discussion}

Based on our survey in China from 2007 to 2019, aphidtransmitted BYDVs were the most prevalent among the insecttransmitted viruses infecting wheat in all tested wheat fields in the

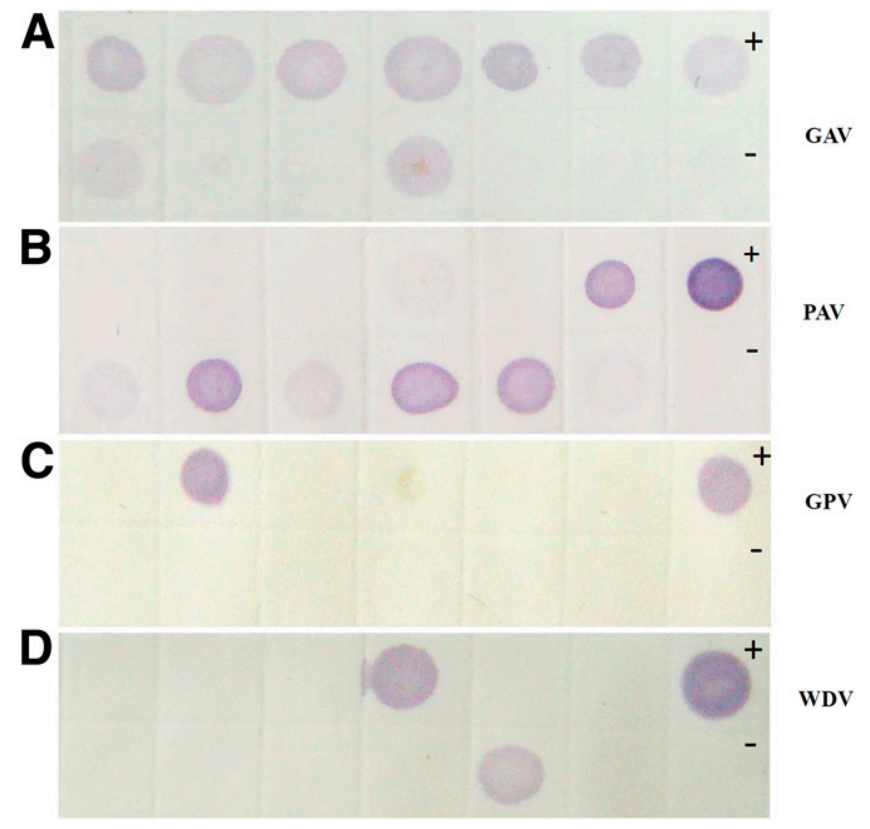

Fig. 2. Representative spot hybridization analysis to detect viruses in samples from Shaanxi in 2013. Hybridization results of total RNA from test samples with four digoxigenin-labeled probes for barley yellow dwarf virus A, GAV; B, PAV; C, GPV; and $\mathrm{D}$, wheat dwarf virus (WDV). For each sample, $1.2 \mu \mathrm{l}$ of total RNA was spotted onto four membranes. Total RNA of samples from fresh leaves infected by laboratory isolates of the respective viruses was separately applied as the positive control $(+)$; total RNA from healthy wheat plants served as the negative control (-).

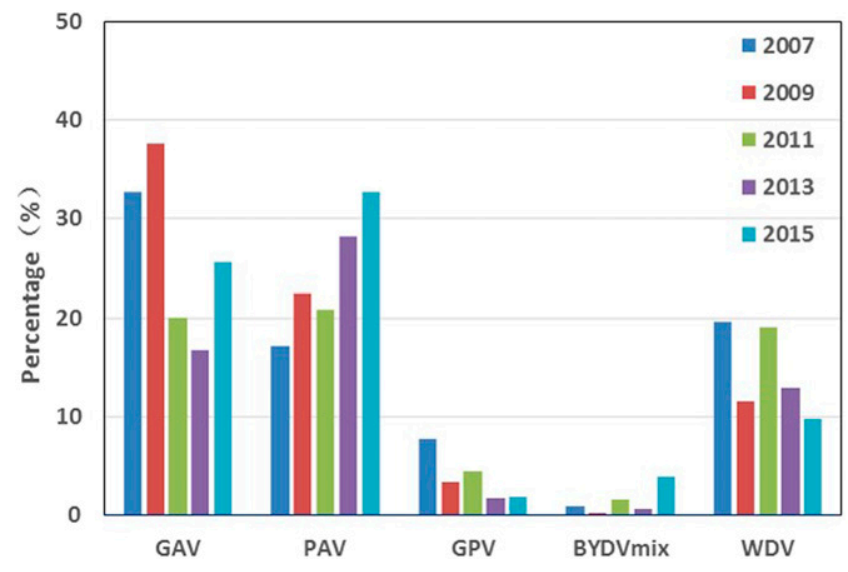

Fig. 3. Mean incidence of barley yellow dwarf virus (BYDV)-GAV, -PAV, and -GPV alone or BYDV mixture (combination with one or two of the other viruses) or wheat dwarf virus (WDV) in samples from five regions from 2007 to 2015. 
different regions (Tables 1 and 2). Notably, the incidence of BYDVGAV had decreased in the northwest and north, whereas BYDVPAV had increased and become the most prevalent virus in recent years (Fig. 5). The leafhopper-transmitted WDV and WYSV were the most common in the northwest $(38.8 \%)$ but below $10 \%$ in the other regions (Fig. 5). In addition, SBPH-transmitted viruses (BYSMV, NCMV, and RBSDV) in wheat differed in their geographical distribution and tended to be localized to the north (31.0\%), central (16.7\%), and east (12.9\%) (Fig. 5). It needs to be clarified that symptomatic or suspicious samples were collected for testing known insect-borne viruses in our investigation, indicating that the disease incidence in this result may be higher than that of random sampling. To some extent, asymptomatic infection with some of these viruses could be happening, depending on a range of factors such as temperature, the intensity of sunlight, virus concentration, sampling period, and so on. Therefore, sampling with symptomatic plants certainly increases the subjectivity, which can be eliminated by random sampling. Nevertheless, the survey of symptomatic samples over a decade provides an important reference value for wheat-infecting virus disease management in China.

BYDVs were first reported in northwestern China in 1960 and caused eight major outbreaks in northern and northwestern China in 1966, 1968, 1970, 1973, 1978, 1980, 1987, and 1999 (Wang et al. 2010). Except for these periods of high incidence, the occurrence of BYDVs has been local in most regions and generally low. In surveys from 2004 to 2006, BYDV-GAV was the predominant virus throughout northern and northwestern China (Y. Liu et al. 2007). In the present study, from 2007 to 2015, BYDV-GAV was most frequent $(29.0 \%)$, BYDV-PAV reached $23.2 \%$, and BYDV-GPV was least frequent (7.4\%). In central, eastern, and southwestern China, BYDV-PAV was always the most frequent for many years; however, in the second survey, BYDV-PAV had become the most frequent not only in these regions but also in the north and northwest. From 2016 to 2019, BYDV-PAV (39.5\%) was already the most prevalent virus, followed by BYDV-GAV (13.4\%). BYDV-GPV (1.1\%), however, had become even more infrequent, in keeping with its general decline during the 30 years after it was first reported as causing an important viral disease on wheat in northern China in the 1980s (Cheng and Zhou 1986). Although the overall incidence of BYDV-GAV has decreased since the second survey, it is worth noting that its incidence has been high ( $80 \%$ of samples) on the Qinghai-Tibet Plateau since 2011. In this region, S. avenae is the predominant aphid species, followed by $S$. graminum and $R$. padi (Liu et al. 2016; Yao et al. 2018), and the annual average temperature of the Qinghai-Tibet Plateau since 1997 has clearly been increasing, especially since 2005 (Yao et al. 2000). As the climate warms, the growing season is also extended, as is the reproductive cycle of the aphid vectors in this region, thereby increasing their populations (Huang et al. 2006). In addition, the BYDV titer has been shown to increase in plants grown under elevated $\mathrm{CO}_{2}$ levels, suggesting that virus diseases in wheat will increase with climate change (Trębicki et al. 2015).

BYDV-PAV has been reported as the most widespread virus species in cereals worldwide (Henry et al. 1992; Jarošová et al. 2013; Rochow 1979), and the genomic sequences of BYDV-PAV isolates from different countries are highly divergent (Wu et al. 2011). On the basis of available sequences in GenBank, BYDV-PAV has been divided into three distinct species: PAV, PAS, and PAV-CN (Jarošová et al. 2013; F. Liu et al. 2007). BYDV-PAV-CN, transmitted efficiently by $R$. padi, S. avenae, and S. graminum, is also highly divergent from other BYDVs. In irrigated lands, the predominant aphid species are often $R$. padi and $S$. avenae, which would be expected

Table 2. Incidence of viruses transmitted by aphids, leafhoppers, or small brown planthopper (SBPH) from 2016 to 2019 in symptomatic wheat samples in China ${ }^{\mathrm{a}}$

\begin{tabular}{|c|c|c|c|c|c|c|c|c|c|c|}
\hline \multirow[b]{2}{*}{ Year, location } & \multirow[b]{2}{*}{$N^{\mathbf{b}}$} & \multicolumn{4}{|c|}{ Aphid-transmitted viruses } & \multicolumn{2}{|c|}{$\begin{array}{c}\text { Leafhopper- } \\
\text { transmitted viruses } \\
\end{array}$} & \multicolumn{3}{|c|}{ SBPH-transmitted viruses } \\
\hline & & GAV & PAV & GPV & Mix & WDV & WYSV & BYSMV & NCMV & RBSDV \\
\hline \multicolumn{11}{|l|}{2016} \\
\hline Northwest & 52 & 10 & 13 & 0 & 0 & 20 & 5 & 0 & 1 & 0 \\
\hline North & 99 & 20 & 18 & 1 & 0 & 10 & 0 & 38 & 0 & 4 \\
\hline Central & 30 & 8 & 12 & 0 & 0 & 0 & 0 & 1 & 0 & 5 \\
\hline Southwest & 26 & 5 & 9 & 0 & 0 & 0 & 0 & 0 & 0 & 0 \\
\hline East & 38 & 3 & 15 & 1 & 2 & 0 & 0 & 0 & 2 & 5 \\
\hline Combined & 245 & 46 & 67 & 2 & 2 & 30 & 5 & 39 & 3 & 14 \\
\hline \multicolumn{11}{|l|}{2017} \\
\hline Northwest & 32 & 9 & 11 & 0 & 0 & 11 & 10 & 0 & 0 & 0 \\
\hline North & 54 & 6 & 21 & 3 & 1 & 0 & 0 & 14 & 0 & 3 \\
\hline Central & 29 & 5 & 9 & 0 & 0 & 0 & 5 & 0 & 0 & 6 \\
\hline Southwest & 39 & 6 & 24 & 0 & 0 & 0 & 2 & 0 & 0 & 0 \\
\hline East & 46 & 3 & 32 & 0 & 0 & 0 & 0 & 0 & 0 & 6 \\
\hline Combined & 200 & 29 & 97 & 3 & 1 & 11 & 17 & 14 & 0 & 15 \\
\hline \multicolumn{11}{|l|}{2018} \\
\hline Northwest & 78 & 12 & 19 & 1 & 0 & 14 & 10 & 0 & 0 & 4 \\
\hline North & 58 & 10 & 15 & 1 & 0 & 0 & 0 & 14 & 0 & 5 \\
\hline Central & 25 & 2 & 14 & 0 & 0 & 0 & 0 & 0 & 0 & 1 \\
\hline Southwest & 34 & 1 & 18 & 0 & 0 & 0 & 0 & 0 & 0 & 0 \\
\hline East & 26 & 0 & 19 & 0 & 0 & 0 & 0 & 0 & 0 & 2 \\
\hline Combined & 221 & 25 & 85 & 2 & 0 & 14 & 10 & 14 & 0 & 12 \\
\hline \multicolumn{11}{|l|}{2019} \\
\hline Northwest & 96 & 10 & 34 & 0 & 0 & 25 & 5 & 0 & 1 & 0 \\
\hline North & 79 & 15 & 38 & 3 & 1 & 15 & 0 & 8 & 1 & 3 \\
\hline Central & 30 & 2 & 17 & 0 & 0 & 0 & 0 & 0 & 0 & 6 \\
\hline Southwest & 59 & 1 & 27 & 0 & 0 & 0 & 0 & 0 & 0 & 0 \\
\hline East & 22 & 0 & 11 & 0 & 0 & 0 & 0 & 0 & 2 & 0 \\
\hline Combined & 286 & 28 & 127 & 3 & 1 & 40 & 5 & 8 & 4 & 9 \\
\hline Total & 952 & 128 & 376 & 10 & 4 & 95 & 37 & 75 & 7 & 50 \\
\hline
\end{tabular}

${ }^{a}$ GAV, PAV, and GPV = barley yellow dwarf viruses, Mix = mixture, WDV = wheat dwarf virus, WYSV = wheat yellow striate virus, BYSMV = barley yellow striate mosaic virus, NCMV = northern cereal mosaic virus, and RBSDV = rice black-streaked dwarf virus.

b Number of samples. 
to transmit BYDV-PAV efficiently; however, $S$. graminum was the most common aphid species in the dry farmlands and higher altitude areas (Hatting et al. 2000). The high incidence of BYDV-PAV in China could be partly explained by the wide range of vector aphids.

Since WDV was first reported in the Czech Republic in 1961, it has spread to all the wheat-growing areas in Europe (Lindblad and Sigvald 2004; Schubert et al. 2007; Vacke 1961). The incidence of wheat dwarf disease has been relatively sporadic but it may cause huge yield losses during an outbreak (Kumar et al. 2015), and it has attracted considerable attention in several European, African, and Asian countries in the last 30 years (Kumar et al. 2014; Lindblad and Areno 2002; Najar et al. 2000). WDV also caused a serious problem in northwestern China in 2008 because favorable environmental conditions supported high populations of $P$. alienus (Wang et al. 2008). Although WDV has been found in other cereal-growing regions of China, the disease has not been devastating because the population of $P$. alienus has been low in these regions (Zhao et al. 2010).

Rice black-streaked dwarf disease (RBSDD), caused by RBSDV, is one of the most important diseases of rice and maize in China (Otuka et al. 2010; Zhang et al. 2001). Recent outbreaks of RBSDV in rice and maize from 2008 to 2013 caused yield losses from $25 \%$ to more than $90 \%$ in northern and eastern China but control measures since then have led to a decline (Miao et al. 2015; Wu et al. 2013). A high incidence of RBSDD has been common in eastern China where japonica rice is grown (Wang et al. 2009). After rice or maize is harvested, RBSDV-infective SBPH moves to grassy weeds and then overwinters in wheat; however, its incidence in wheat is generally low and does not cause serious losses (Matsukura et al. 2019;

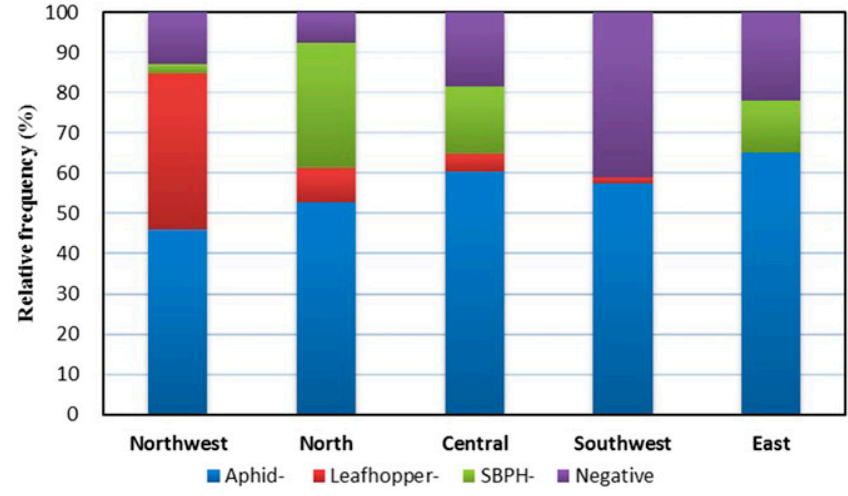

Fig. 5. Relative frequency of aphid-, leafhopper-, or small brown planthoppertransmitted viruses in wheat sampled from 2016 to 2019 in China. Negative = samples negative for tested viruses.
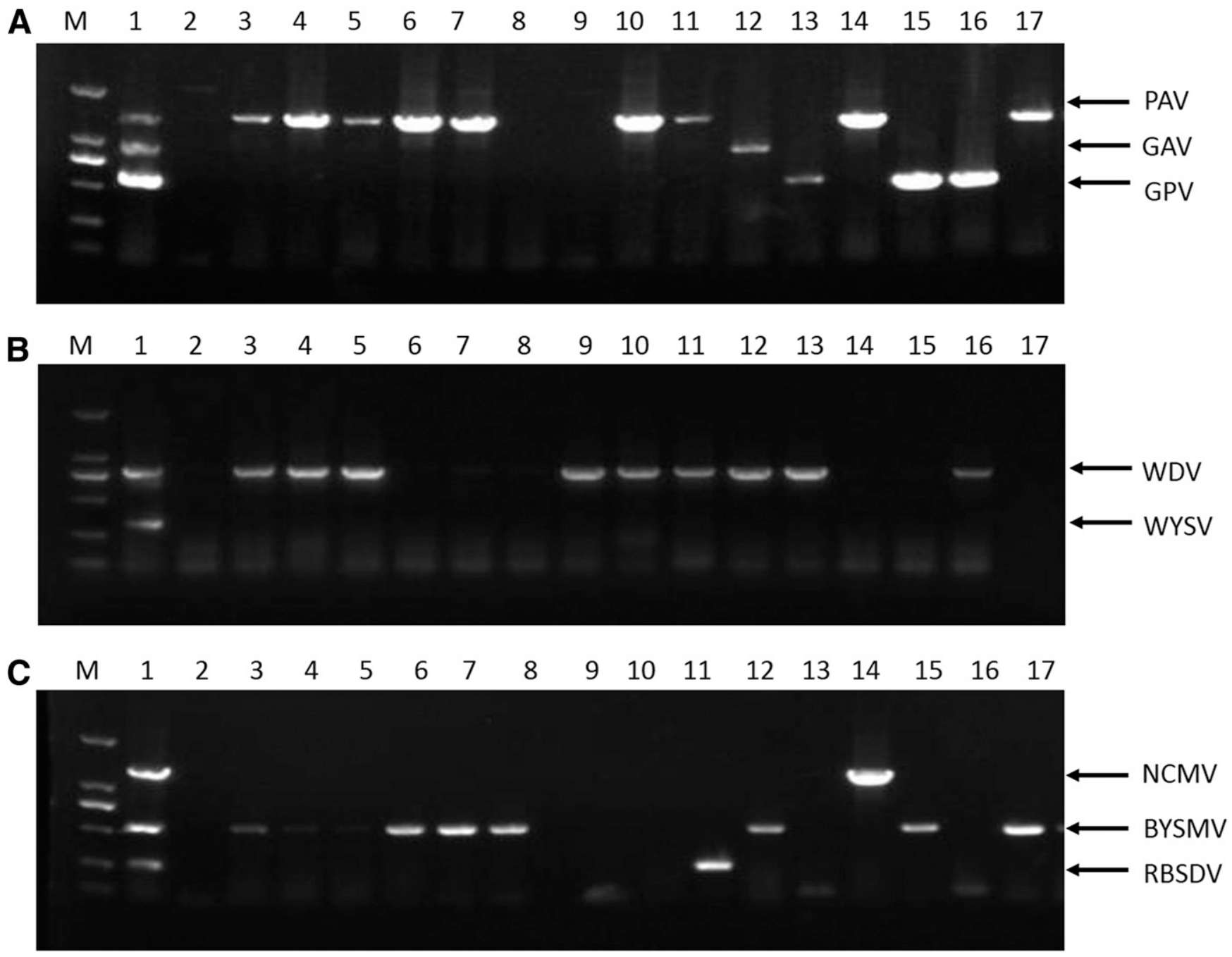

Fig. 4. Diagnosis of virus infection using three sets of multiplex reverse-transcription (RT)-PCR system. A, Barley yellow dwarf virus PAV (1,466 bp), GAV (957 bp), and GPV (606 bp); B, wheat dwarf virus (WDV) (783 bp) and wheat yellow striate virus (WYSV) (322 bp); and C, northern cereal mosaic virus (NCMV) (1,296 bp), barley yellow striate mosaic virus (BYSMV) (565 bp), and rice black-streaked dwarf virus (RBSDV) (273 bp). Lane M, marker DL2000; lane 1, RT-PCR products from a mixture of total RNA of each virus in equal amounts (positive control); lane 2, no-template control (distilled water); lanes 3 to 17, products of samples collected from north region (Shanxi and Hebei provinces) in 2019. Arrows on the right mark locations of expected PCR products. 
Wang et al. 2009). In the present study, almost all RBSDV-positive samples in wheat fields were found in eastern China (e.g., Shandong and Jiangsu provinces) in RBSDV-infected rice fields, suggesting that wheat is a key local source of RBSDV (W. Liu et al. 2018). Thus, controlling SBPH and RBSDV in wheat fields should be an effective measure to prevent RBSDV outbreaks in rice fields.

NCMV, a rhabdovirus transmitted by SBPH, occurred in cereals in East Asia, including Japan, Korea, and China, during the 1970s and 1980s (Lundsgaard et al. 1984). In the present 4-year survey, the incidence of NCMV was very low (seven positive samples). NCMV seems to infect only wheat, barley, rye, and oat, not other gramineous plants such as maize, rice, and smooth bromegrass (Zhang et al. 1981). Thus, the narrow host range and high vector specificity may account for its low incidence over the past 40 years.

However, rhabdoviruses that have either been newly found or recently emerged in northern and northwestern China may create new problems for cereal production. In China, BYSMV was first reported in 2014 and was mainly found in wheat fields in Hebei in northern China, while it also distributed in northwestern and eastern regions (Di et al. 2014). In spring 2016, a new cereal-infecting rhabdovirus, WYSV transmitted by the leafhopper P. alienus, was also discovered in wheat samples collected from Shaanxi Province in northwestern China (Y. Liu et al. 2018). Our surveys from 2016 to 2019 revealed that BYSMV was present in China only in some northern regions. Similarly, the incidence of WYSV has been low for over 4 years, with only local epidemics in northwestern and central China. Thus far, WYSV has not been reported in other countries.

Overall, our large-scale survey revealed that aphid-transmitted BYDVs have been the most common viruses in various parts of China, followed by leafhopper-transmitted WDV, in spite of its varying incidence. The three SBPH-transmitted viruses (BYSMV, NCMV, and RBSDV) and leafhopper-transmitted WYSV only caused local epidemics, mainly in northern and northwestern China. Epidemics caused by insect-transmitted viruses are largely related to the abundance of the vector during the early growth stages of cereal crops. With global warming, insect-transmitted viruses are expected to gain more importance, even in cooler regions. Longer, warmer periods in autumn lead to longer flight activities of the vectors, increasing the risk of infection for winter cereals. Field management of insect-transmitted viruses is directed at depressing the vector population and eliminating any bridge hosts, and extensive efforts are directed at developing resistant or tolerant cultivars. Monitoring these insect-transmitted viruses enhances our understanding of the epidemiology of these viral diseases and is essential for developing management strategies that are specifically adapted for local conditions.

\section{Acknowledgments}

We thank Y. Wu (Northwest A\&F University) and Y. Cao (Shanxi Academy of Agricultural Sciences) for assistance in field surveys and B. E. Hazen (Willows End scientific editing and writing, Cortland, NY, U.S.A.) for critical reading and revising of the manuscript.

\section{Literature Cited}

Cheng, Z. M., and Zhou, G. H. 1986. Purification and serological studies on the GPV strain of wheat yellow dwarf virus. Chin. J. Virol. 12:275-277 (in Chinese).

Conti, M. 1969. Investigations on the bullet-shaped virus of cereals isolated in Italy from planthoppers. J. Phytopathol. 66:275-279.

Di, D. P., Zhang, Y. L., Yan, C., Yan, T., Zhang, A. H., Yang, F., Cao, X. L., Li, D. W., Lu, Y. G., Wang, X. B., and Miao, H. Q. 2014. First report of Barley yellow striate mosaic virus on wheat in China. Plant Dis. 98:1450.

Du, Z. Z., Fu, Y. M., Liu, Y., and Wang, X. F. 2020. Transmission characteristics of Wheat yellow striate virus by its leafhopper vector Psammotettix alienus. Plant Dis. 104:222-226.

Hatting, J. L., Poprawski, T. J., and Miller, R. M. 2000. Prevalences of fungal pathogens and other natural enemies of cereal aphids (Homoptera: Aphididae) in wheat under dryland and irrigated conditions in South Africa. BioControl 45:179-199.

Henry, M., Francki, R. I. B., and Wallwork, H. 1992. Occurrence of barley yellow dwarf virus in cereals and grasses of the low rainfall wheatbelt of South Australia. Plant Pathol. 41:713-721.

Hogenhout, S. A., Ammar, E. D., Whitfield, A. E., and Redinbaugh, M. G. 2008. Insect vector interactions with persistently transmitted viruses. Annu. Rev. Phytopathol. 46:327-359.
Huang, X. L., Qiao, G. X., and Lei, F. M. 2006. Diversity and distribution of aphids in Qinghai-Tibetan Plateau-Himalayas. Ecol. Entomol. 31:608-615.

Ingwell, L. L., and Bosque-Perez, N. A. 2015. New experimental hosts of Barley yellow dwarf virus among wild grasses, with implications for grassland habitats. Plant Pathol. 64:1300-1307.

Jarošová, J., Chrpová, J., Šíp, V., and Kundu, J. K. 2013. A comparative study of the Barley yellow dwarf virus species PAV and PAS: Distribution, accumulation and host resistance. Plant Pathol. 62:436-443.

Jin, W., Zhang, J. L., Liu, Y., and Wang, X. F. 2015. Development and application of nucleic acid spot hybridization (NASH) assay for rapid detection of wheat dwarf virus. Plant Prot. 41:100-103 (in Chinese).

Jin, Z. B., Wang, X. F., Chang, S. J., and Zhou, G. H. 2004. The complete nucleotide sequence and its organization of the genome of Barley yellow dwarf virus-GAV. Sci. China Ser. C 47:175-182.

Krueger, E. N., Beckett, R. J., Gray, S. M., and Miller, W. A. 2013. The complete nucleotide sequence of the genome of Barley yellow dwarf virus-RMV reveals it to be a new Polerovirus distantly related to other yellow dwarf viruses. Front. Microbiol. 4:205.

Kumar, J., Kumar, J., Singh, S., Shukla, V., Singh, S. P., and Tuli, R. 2015 Prevalence of Wheat dwarf India virus in wheat in India. Curr. Sci. 108: 260-265.

Kumar, J., Kumar, J., Singh, S. P., and Tuli, R. 2014. Association of satellites with a mastrevirus in natural infection: Complexity of wheat dwarf India virus disease. J. Virol. 88:7093-7104.

Lindblad, M., and Areno, P. 2002. Temporal and spatial population dynamics of Psammotettix alienus, a vector of wheat dwarf virus. Int. J. Pest Manage. 48: 233-238.

Lindblad, M., and Sigvald, R. 2004. Temporal spread of wheat dwarf virus and mature plant resistance in winter wheat. Crop Prot. 23:229-234

Liu, F., Wang, X. F., Liu, Y., Xie, J. J., Gray, S. M., Zhou, G. H., and Gao, B. D. 2007. A Chinese isolate of barley yellow dwarf virus-PAV represents a third distinct species within the PAV serotype. Arch. Virol. 152:1365-1373.

Liu, N., Yan, J. H., Yao, Q., and Guo, Q. Y. 2016. Investigation on occurrence of wheat and barley yellow dwarf in Qinghai province. Jiangsu Agric. Sci. 44: 154-158 (in Chinese).

Liu, W. W., Hajano, J. U., and Wang, X. F. 2018. New insights on the transmission mechanism of tenuiviruses by their vector insects. Curr. Opin. Virol. 33:13-17.

Liu, W. W., Zhang, X. W., Wu, N., Ren, Y. D., and Wang, X. F. 2019. High diversity and functional complementation of alimentary canal microbiota ensure small brown planthopper to adapt different biogeographic environments. Front. Microbiol. 10:2953

Liu, Y., Du, Z. Z., Wang, H., Zhang, S., Cao, M. J., and Wang, X. F. 2018 Identification and characterization of Wheat yellow striate virus, a nove leafhopper-transmitted nucleorhabdovirus infecting wheat. Front. Microbiol. $9: 468$

Liu, Y., Sun, B., Wang, X. F., Zheng, C. L., and Zhou, G. H. 2007. Three digoxigenin-labeled cDNA probes for specific detection of the natural population of Barley yellow dwarf viruses in China by dot-blot hybridization. J. Virol. Methods 145:22-29.

Lundsgaard, T., Tien, P., and Toriyama, S. 1984. The antigens of wheat rosette stunt and northern cereal mosaic viruses are related. J. Phytopathol. 111: 232-235.

Manurung, B., Witsack, W., Mehner, S., Grüntzig, M., and Fuchs, E. 2004. The epidemiology of Wheat dwarf virus in relation to occurrence of the leafhopper Psammotettix alienus in middle-Germany. Virus Res. 100:109-113.

Matsukura, K., Sanada-Morimura, S., Fujii, T., and Matsumura, M. 2019. Potential risks of Poaceous plants as infectious sources of rice black-streaked dwarf virus transmitted by the small brown planthopper, Laodelphax striatellus. Plant Dis. 103:1244-1248

Miao, H. Q., Di, D. P., Zhang, A. H., Lu, Y. G., Tian, L. Z., Stewart, L. R., and Redinbaugh, M. G. 2015. Efficient inoculation of Rice black-streaked dwarf virus to maize using Laodelphax striatellus Fallen. J. Phytopathol. 163:529-535.

Miller, W. A., and Rasochová, L. 1997. Barley yellow dwarf viruses. Annu. Rev. Phytopathol. 35:167-190.

Najar, A. K. M., Makkouk, H., Boudhir, S. G., Kumari, R., Zarouk, R., Bessai, R., and Othman, F. B. 2000. Viral diseases of cultivated legume and cereal crops in Tunisia. Phytopathol. Mediterr. 39:423-432.

Nault, L. R., and Ammar, E. D. 1989. Leafhopper and planthopper transmission of plant viruses. Annu. Rev. Entomol. 34:503-529.

Otuka, A., Matsumura, M., Sanada-Morimura, S., Takeuchi, H., Watanabe, T., Ohtsu, R., and Inoue, H. 2010. The 2008 overseas mass migration of the small brown planthopper, Laodelphax striatellus, and subsequent outbreak of rice stripe disease in western Japan. Appl. Entomol. Zool. 45:259-266.

Parizipour, M. H., Schubert, J., Behjatnia, S. A., Afsharifar, A., Habekuss, A., and Wu, B. 2017. Phylogenetic analysis of Wheat dwarf virus isolates from Iran. Virus Genes 53:266-274.

Rochow, W. F. 1979. Field variants of barley yellow dwarf virus: Detection and fluctuation during twenty years. Phytopathology 69:655-660.

Rotenberg, D., Bockus, W. W., Whitfield, A. E., Hervey, K., Baker, K. D., Ou, Z., Laney, A. G., De Wolf, E. D., and Appel, J. A. 2016. Occurrence of viruses and associated grain yields of paired symptomatic and nonsymptomatic tillers in Kansas winter wheat fields. Phytopathology 106:202-210. 
Schubert, J., Habekuss, A., Kazmaier, K., and Jeske, H. 2007. Surveying cerealinfecting geminiviruses in Germany-Diagnostics and direct sequencing using rolling circle amplification. Virus Res. 127:61-70.

Tanno, F., Nakatsu, A., Toriyama, S., and Kojima, M. 2000. Complete nucleotide sequence of Northern cereal mosaic virus and its genome organization. Arch. Virol. 145:1373-1384.

Trębicki, P., Nancarrow, N., Cole, E., Bosque-Pérez, N. A., Constable, F. E., Freeman, A. J., Rodoni, B., Yen, A. L., Luck, J. E., and Fitzgerald, G. J. 2015. Virus disease in wheat predicted to increase with a changing climate. Glob. Change Biol. 21:3511-3519.

Vacke, J. 1961. Wheat dwarf virus disease [Virová zakrslost pšenice]. Biol. Plant. $3: 228-233$.

Wang, H., Liu, Y., Zhang, L., Kundu, J. K., Liu, W. W., and Wang, X. F. 2019. ADP ribosylation factor 1 facilitates spread of wheat dwarf virus in its insect vector. Cell. Microbiol. 21:e13047.

Wang, H.-D., Cheng, J.-P., Wang, A.-G., Jiang, X.-H., and Adams, M. J. 2009. Studies on the epidemiology and yield losses from rice black-streaked dwarf disease in a recent epidemic in Zhejiang province, China. Plant Pathol. 58: $815-825$.

Wang, J. F., Liu, S. B., Wu, B. L., Xie, J. J., and Wang, X. F. 2008. Identification and analyses of the pathogen causing wheat dwarf in Hancheng of Shaanxi province, China. Plant Prot. 34:17-21 (in Chinese).

Wang, X. F., Liu, Y., Han, C. G., Wu, Y. F., and Zhao, Z. H. 2010. Present situation and development strategies for the research and control of wheat viral diseases. Plant Prot. 36:13-19 (in Chinese).

Wei, J. Y., Xu, W. Y., and Wang, X. B. 2018. Progress in plant rhabdoviruses in China. Plant Prot. 44:19-23 (in Chinese).

Wu, B. L., Blanchard-Letort, A., Liu, Y., Zhou, G. H., Wang, X. F., and Elena, S. F. 2011. Dynamics of molecular evolution and phylogeography of Barley yellow dwarf virus-PAV. PLoS One 6:e16896.

Wu, W. Q., Guo, X. G., Zhang, H. M., Yang, J., Lv, M. F., and Chen, J. P. 2013. Simultaneous detection and survey of three rice viruses in China. Plant Dis. 97: 1181-1186.

Xie, J. J., Wang, X. F., Liu, Y., Peng, Y. F., and Zhou, G. H. 2007. First report of the occurrence of wheat dwarf virus in wheat in China. Plant Dis. 91:111.
Yan, T., Zhu, J. R., Di, D. P., Gao, Q., Zhang, Y. L., Zhang, A. H., Yan, C., Miao, H. Q., and Wang, X. B. 2015. Characterization of the complete genome of barley yellow striate mosaic virus reveals a nested gene encoding a small hydrophobic protein. Virology 478:112-122.

Yang, F., Zhang, A. H., Meng, F. S., Huo, L. Z., Li, X. W., Di, D. P., and Miao, H. Q. 2018. Distribution and genetic diversity of barley yellow striate mosaic virus in northern China. Sci. Agric. Sin. 51:279-289 (in Chinese).

Yao, T. D., Liu, X. D., Wang, N. L., and Shi, Y. F. 2000. Amplitude of climatic changes in Qinghai-Tibetan Plateau. Chin. Sci. Bull. 45:1236-1243.

Yao, X. B., Wang, W. F., Li, Y., Liu, H. C., Lei, X. P., Pang, B., and Cirenyangla. 2018. Identification of strain of Tibet barley yellow dwarf virus and analysis of transmission capabilities of mediating aphid. Tibet J. Agric. Sci. 3:5-8 (in Chinese)

Zhang, H. M., Chen, J. P., Lei, J., and Adams, M. J. 2001. Sequence analysis shows that a dwarfing disease on rice, wheat and maize in china is caused by Rice black-streaked dwarf virus. Eur. J. Plant Pathol. 107:563-567.

Zhang, P. P., Liu, Y., Liu, W. W., Massart, S., and Wang, X. F. 2017. Simultaneous detection of wheat dwarf virus, northern cereal mosaic virus, barley yellow striate mosaic virus and rice black-streaked dwarf virus in wheat by multiplex RT-PCR. J. Virol. Methods 249:170-174.

Zhang, S. X., Shu, X. Z., Zhou, G. Z., Fu, C. S., Li, Z. L., and Wang, L. Y. 1981 Preliminary studies on the hosts range of wheat rosette disease caused by northern cereal mosaic virus. Acta Phytopathol. Sin. 11:7-10 (in Chinese)

Zhang, S. X., and Zhou, G. H. 1987. Identification on strain of wheat yellow dwarf virus (WYDV) transmitted by Schizaphis graminum and Rhopalosiphum padi. Acta Phytopathol. Sin. 17:102-105 (in Chinese).

Zhang, W. W., Cheng, Z. M., Xu, L., Wu, M. S., Waterhouse, P., Zhou, G. H., and Li, S. F. 2009. The complete nucleotide sequence of the barley yellow dwarf GPV isolate from China shows that it is a new member of the genus Polerovirus. Arch. Virol. 154:1125-1128.

Zhao, L. Q., Xiao, B., Dai, W., and Zhang, Y. L. 2010. Taxonomy and morphology of the vector leafhopper Psammotettix striatus (L.) (Hemiptera: Cicadellidae: Deltocephalinae). Entomotaxonomia 32:179-184 (in Chinese).

Zhou, G. H., Cheng, Z. M., Qian, Y. T., Zhang, X. C., and Rochow, W. F. 1984 Serological identification of Luteoviruses of small grains in China. Plant Dis. 68:710-713. 